\title{
Tratamento para obtenção de TaC em superfície de grafite. Parte II: eletrodeposição em meio de fluoretos fundidos
}

\author{
(TaC formation on graphite surface. \\ Part II: electrodeposition from molten fluorides)
}

\author{
H. J. Izário Fo 1, F. Vernilli Jr. ${ }^{2}$, D. V. B. S. Pinto ${ }^{3}$, N. Baccan ${ }^{4}$, A. F. Sartori ${ }^{2}$ \\ ${ }^{1}$ Departamento de Engenharia Química - FAENQUIL \\ ${ }^{2}$ Departamento de Engenharia de Materiais - FAENQUIL \\ C. P. 116, 12600-000,Lorena, SP. \\ vernilli@demar.faenquil.br \\ ${ }^{3}$ Instituto de Química da Universidade de S. Paulo - USP \\ ${ }^{4}$ Instituto de Química da Universidade de Campinas - UNICAMP
}

\begin{abstract}
Resumo
Este trabalho apresenta a técnica de eletrodeposição de tântalo em meio de fluoretos fundidos, seguida de tratamento térmico para formação do carbeto de tântalo, como uma alternativa de pré-tratamento para tubos de grafite utilizados em determinações analíticas de espectrometria de absorção atômica em forno de grafite. Os experimentos de eletrodeposição foram executados utilizando-se como solução eletrolítica a mistura eutética LiF-NaF-KF com adição de 15\% em massa de $\mathrm{K}_{2} \mathrm{TaF}_{7}$. Os ânodos de tântalo foram provenientes de sucata comercial de tântalo, o cátodo foi o próprio tubo de grafite a ser revestido. O revestimento de tântalo foi obtido com alta eficiência de corrente a $750{ }^{\circ} \mathrm{C}$, em densidade de corrente catódica de $20 \mathrm{~mA} . \mathrm{cm}^{-2}$ e tempo de eletrólise de $120 \mathrm{~min}$., sob atmosfera controlada de argônio. $\mathrm{O}$ tratamento térmico realizado em atmosfera de argônio, possibilitou a formação de uma perfeita camada de carbeto de tântalo, confirmada através de análise de difratometria de raios X. O depósito, analisado por microscopia eletrônica de varredura (M.E.V.), mostrou-se liso, aderente ao substrato, sem porosidades, incrustações ou microtrincas.
\end{abstract}

Palavras-chave: carbeto de tântalo, eletrodeposição, fluoretos fundidos, grafite.

\section{INTRODUÇÃO}

A espectrometria de absorção atômica com atomização eletrotérmica em forno de grafite, é um método analítico que apresenta alta sensibilidade de detecção. Muitos analistas realizam prétratamentos nos tubos de grafite de maneira a minimizar interferências durante a análise; estes pré-tratamentos consistem na formação de carbeto na superfície do tubo [1].

A viabilidade da eletrodeposição de metais refratários em meio

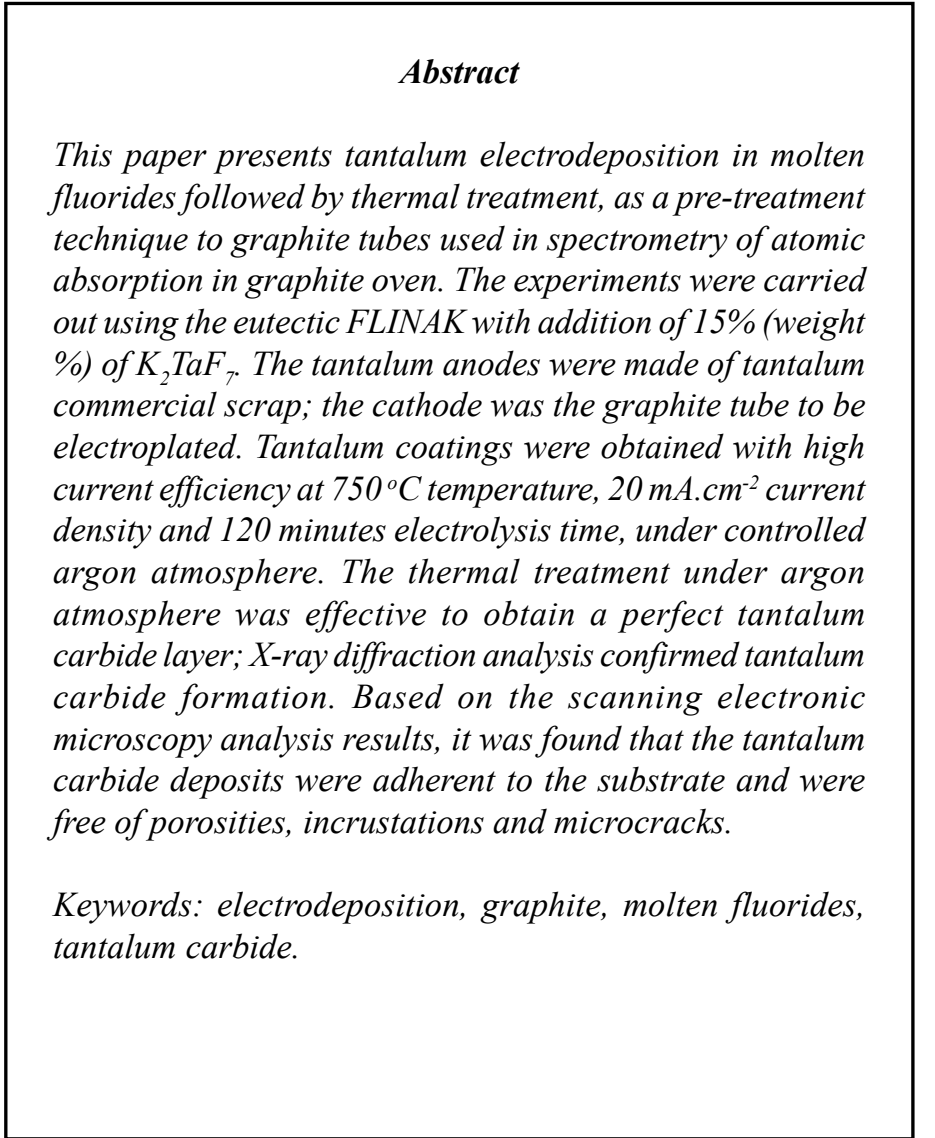

de sais fundidos foi apresentada em vários trabalhos [2-5]. A maioria dos estudos são executados em meio de fluoretos fundidos, especialmente misturas de fluoretos de metais alcalinos, que apresentam propriedades físico-químicas adequadas para a eletrodeposição destes metais, tais como: baixo ponto de fusão, alta condutividade elétrica, baixa pressão de vapor e extensa faixa de potenciais de estabilidade. Além disso, os íons fluoretos formam com o tântalo complexos bastante estáveis, que possibilitam a formação de revestimentos compactos e aderentes. 
Neste trabalho foram feitos ensaios de eletrodeposição de tântalo sobre tubos de grafite, seguidos de tratamento térmico para formação de carbeto de tântalo.

Os experimentos de eletrodeposição de tântalo sobre grafite foram realizados utilizando-se o solvente eutético ternário LiFNaF-KF denominado FLINAK, com adição de $\mathrm{K}_{2} \mathrm{TaF}_{7}$ (heptafluortantalato de potássio).

As condições de operação adotadas para o eletrorrevestimento dos tubos de grafite foram definidas a partir do trabalho de Mellors et al [2] e com base nos resultados obtidos em estudos feitos para a otimização do eletrorrevestimento de aço e cobre, com tântalo, em meio de fluoretos fundidos [6]. Mellors et al [2] foram bem sucedidos quando eletrorrevestiram substratos como aço, grafite e cobre, com nióbio e tântalo, em meio de fluoretos fundidos, em densidade de corrente catódica de aproximadamente $25 \mathrm{~mA} . \mathrm{cm}^{-2}$ e temperatura de $750{ }^{\circ} \mathrm{C}$. No trabalho de tese sobre a eletrodeposição de tântalo utilizando aço e cobre como substratos [6], foi feito um estudo criterioso da influência dos parâmetros eletroquímicos, densidade de corrente, temperatura e tempo de eletrólise, sobre a morfologia e a qualidade dos revestimentos. Depósitos de tântalo lisos e aderentes ao substrato, sem porosidades, incrustações ou microtrincas foram obtidos entre $20 \mathrm{~mA} \cdot \mathrm{cm}^{-2}$ e $50 \mathrm{~mA} \mathrm{~cm}{ }^{-2}$. Quanto ao parâmetro temperatura, observou que à $750^{\circ} \mathrm{C}$ foram depositados revestimentos de tântalo isentos de defeitos; em temperaturas próximas a $800{ }^{\circ} \mathrm{C}$, além da excessiva volatilização do eletrólito, os depósitos foram pulverulentos. No que diz respeito ao tempo de eletrólise, bons revestimentos foram depositados em tempos de eletrólise de 30 min. até $120 \mathrm{~min}$. Assim, neste trabalho, as condições de operação adotadas para o eletrorrevestimento dos tubos de grafite foram: densidade de corrente de $20 \mathrm{~mA} . \mathrm{cm}^{-2}$, tempo de duração da eletrólise de 120 min. e temperatura de $750{ }^{\circ} \mathrm{C}$.

O tratamento térmico dos tubos revestidos com tântalo foi feito, inicialmente, em forno Astro com elemento resistivo de grafite. $\mathrm{O}$ aquecimento é controlado por microprocessador, que possibilita a utilização de taxas de aquecimento lentas. Este forno trabalha com baixo vácuo $\left(\approx 1 \times 10^{-2} \mathrm{MPa}\right)$ e a atmosfera pode ser inerte ou redutora. Com o uso deste forno, sob atmosfera de argônio, a superfície dos tubos de grafite (02 amostras) sofreu oxidação, impossibilitando a formação da camada de carbeto de tântalo. O tratamento térmico dos outros tubos (03 amostras) foi então realizado em forno Tripolar, com aquecimento resistivo de tântalo; a atmosfera de trabalho era inerte, podendo atingir aproximadamente $1 \times 10^{-8} \mathrm{MPa}$.

Os depósitos de carbeto de tântalo sobre grafite, foram analisados através de difratometria de raios X. As características da superfície dos depósitos e da interface substrato/revestimento foram observadas por microscopia eletrônica de varredura (MEV).

\section{EXPERIMENTAL}

Os experimentos de eletrodeposição foram realizados utilizandose o solvente eutético LiF-NaF-KF (29,2 - 11,7 - 59,1\% em massa, respectivamente), com adição de $15 \%$ em massa de $\mathrm{K}_{2} \mathrm{TaF}_{7}$ (heptafluortantalato de potássio).

Os revestimentos de tântalo foram obtidos em uma célula eletrolítica de aço inoxidável, com cadinho de níquel em seu interior, dotada de dispositivos para trabalhar sob vácuo e atmosfera inerte [7]. A corrente constante foi suprida por uma fonte de tensão da Tectrol (0-5 A). A Fig. 1 mostra o esquema da célula de eletrólise.

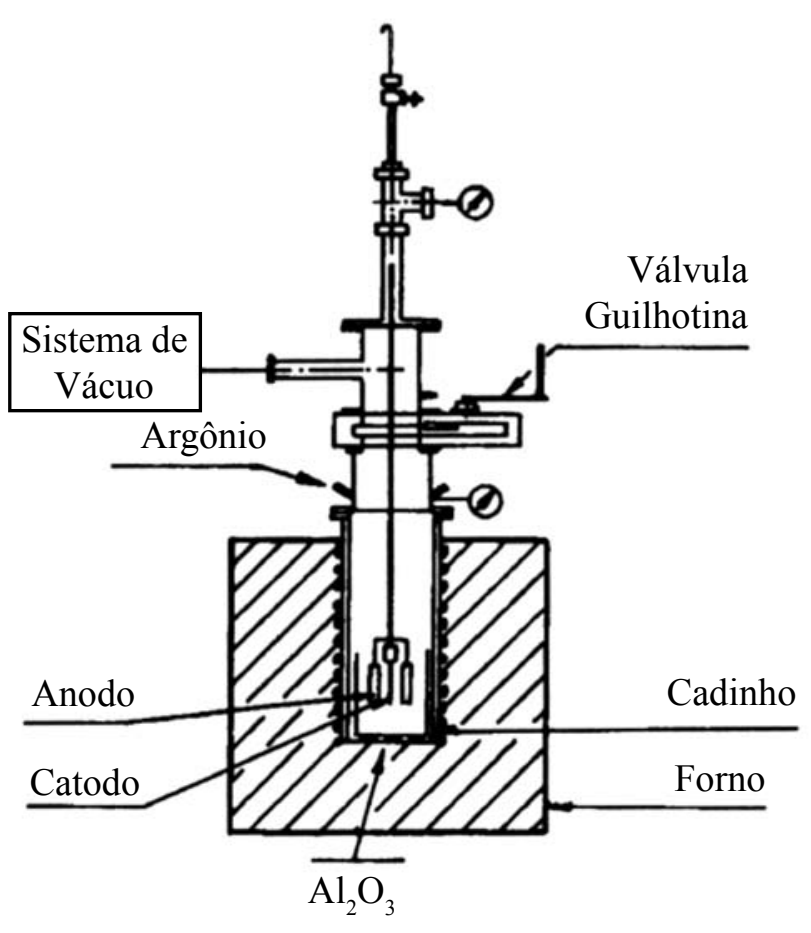

Figura 1: Esquema geral da célula de eletrólise. [Figure 1: Electrolysis cell general outline.]

Os ânodos de tântalo, de 6,6 mm de diâmetro e 41 mm de comprimento, eram provenientes da fusão via feixe eletrônico de sucata comercial de tântalo e posterior forjamento do lingote obtido. $\mathrm{O}$ cátodo foi o tubo de grafite a ser revestido; foram utilizados tubos de grafite sem revestimento pirolítico, fornecidos pela Perkin Elmer, com $6 \mathrm{~mm}$ de diâmetro interno, $28 \mathrm{~mm}$ de comprimento e $1 \mathrm{~mm}$ de espessura de parede.

Os fluoretos de lítio, sódio e potássio, após terem sido pesados nas devidas proporções, foram secos individualmente à $120^{\circ} \mathrm{C}$ durante 48 horas em estufa a vácuo. Após resfriamento, os sais foram misturados em almofariz e acondicionados no cadinho de níquel, que foi então transferido para a célula eletrolítica para que a mistura de sais fosse submetida a uma secagem sob vácuo até $300{ }^{\circ} \mathrm{C}$. Após essa etapa, foi injetado argônio na célula e os sais foram levados a fundir à $500^{\circ} \mathrm{C}$. Após resfriamento do banho, adicionou-se o sal de tântalo, $\mathrm{K}_{2} \mathrm{TaF}_{7}$, e procedeu-se a nova secagem, seguida de fusão sob atmosfera de argônio a $550^{\circ} \mathrm{C}$.

Tabela I - Condições do tratamento térmico no forno tripolar. [Table I: Conditions of the thermal treatment accomplished in the tripolar furnece.]

\begin{tabular}{cccc}
\hline Etapa & $\begin{array}{c}\text { Temperatura } \\
\left({ }^{\circ} \mathrm{C}\right)\end{array}$ & \multicolumn{2}{c}{ Tempo (min.) } \\
rampa & isoterma \\
\hline 1 & 800 & 2 & 2 \\
\hline 3 & 2100 & 30 & 60 \\
\hline 2 & 20 & 30 & - \\
\hline
\end{tabular}

Atmosfera de Argônio $\left(3 \times 10^{-8} \mathrm{MPa}\right)$ 
Os eletrodos de tântalo, antes de serem utilizados, foram submetidos a tratamento de superfície: polimento até lixa 600 e decapagem com solução de $\mathrm{H}_{2} \mathrm{SO}_{4}$ : $\mathrm{HNO}_{3}$ : HF na proporção 50 : $20: 20 \% \mathrm{v} / \mathrm{v}$, lavagem com água destilada e detergente, seguida de lavagem em água destilada e acetona, e secagem com ar quente. Os tubos de grafite, utilizados como cátodos, foram lavados com água destilada e acetona, e secos com ar quente. Todos os reagentes utilizados neste trabalho foram de pureza analítica.

Durante os experimentos de eletrodeposição, foi mantida atmosfera de argônio dentro da célula. Uma válvula tipo guilhotina foi usada para manter a atmosfera e temperatura da célula durante a troca de eletrodos.

O sal retido no cátodo, após resfriamento, forma uma camada muito densa e compacta sobre o tubo. A remoção desta camada, sem comprometimento do tubo, deve ser realizada mediante lavagem em sistema de ultra-som de todo o conjunto, suporte e tubo, em meio de água destilada quente $\left(80{ }^{\circ} \mathrm{C}\right)$. Após remoção do sal incrustado, o tubo foi lavado em dispositivo de ultra-som, em meio de acetona, e seco em estufa durante 60 minutos.

O tratamentos térmico dos tubos revestidos através de eletrólise foi realizado em forno Tripolar, com elemento resistivo de tântalo no formato de uma barca de aproximadamente $1 / 2$ " x 1 " x 5", que também funciona como porta-amostra. $\mathrm{O}$ aquecimento é controlado por reostato e a leitura da temperatura é realizada com pirômetro ótico. A atmosfera de trabalho é vácuo, podendo atingir $1 \times 10^{-8} \mathrm{MPa}$. As condições do tratamento realizado são apresentadas na Tabela I.

A formação de carbeto de tântalo foi confirmada através de análise por difratometria de raios $\mathrm{X}$; a homogeneidade do revestimento e a morfologia dos grãos foram avaliadas através de microscopia eletrônica de varredura (M.E.V.). Para realizar as análises descritas, os tubos revestidos, após o tratamento térmico, foram cortados longitudinalmente e, posteriormente, transversalmente.

\section{RESULTADOS E DISCUSSÃO}

O depósito de tântalo obtido através da eletrólise em meio de fluoretos fundidos, pode ser considerado de boa qualidade, visto ser liso, aderente, homogêneo, sem porosidades, incrustações ou microtrincas.

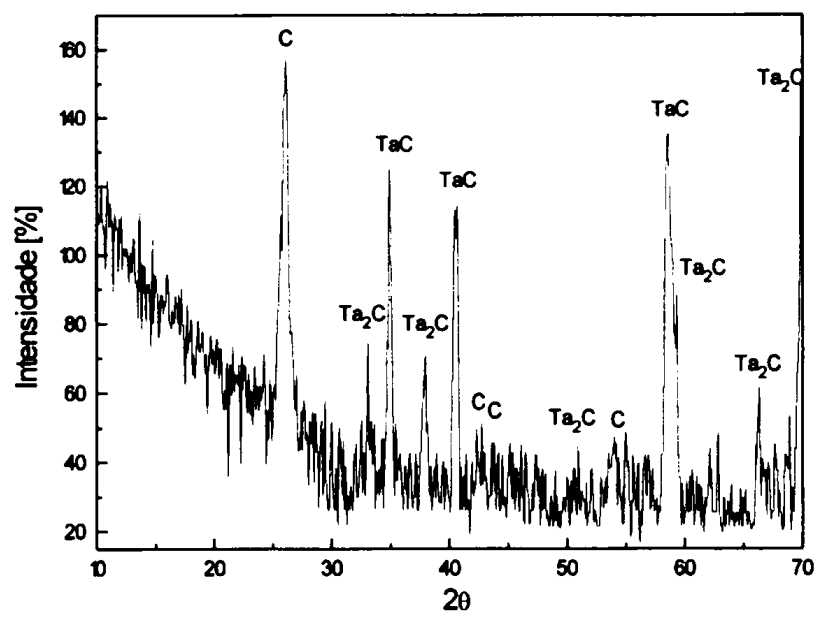

Figura 2: Difratograma de raios $\mathrm{X}$ do carbeto de tântalo obtido por eletrólise em meio de fluoretos fundidos, seguida de tratamento térmico à $2100^{\circ} \mathrm{C}$. [Figure 2: X-ray diffraction pattern of the tantalum carbide obtained from molten fluoride electrolysis, followed by thermal treatment at $2100{ }^{\circ} \mathrm{C}$.]

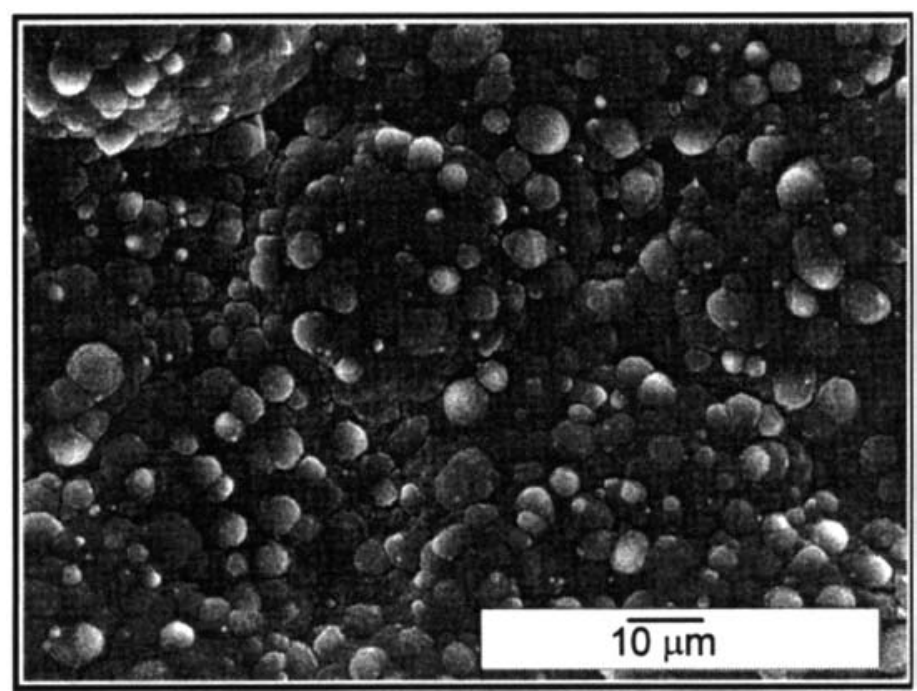

Figura 3:Micrografia obtida por MEV de um revestimento de carbeto de tântalo sobre grafite, obtido por eletrólise em meio de fluoretos fundidos, seguida de tratamento térmico à $2100^{\circ} \mathrm{C}$.

[Figure 3: SEM micrograph of a tantalum carbide coating on graphite, obtained from molten fluoride electrolysis, followed by thermal treatment at $\left.2100{ }^{\circ} \mathrm{C}.\right]$

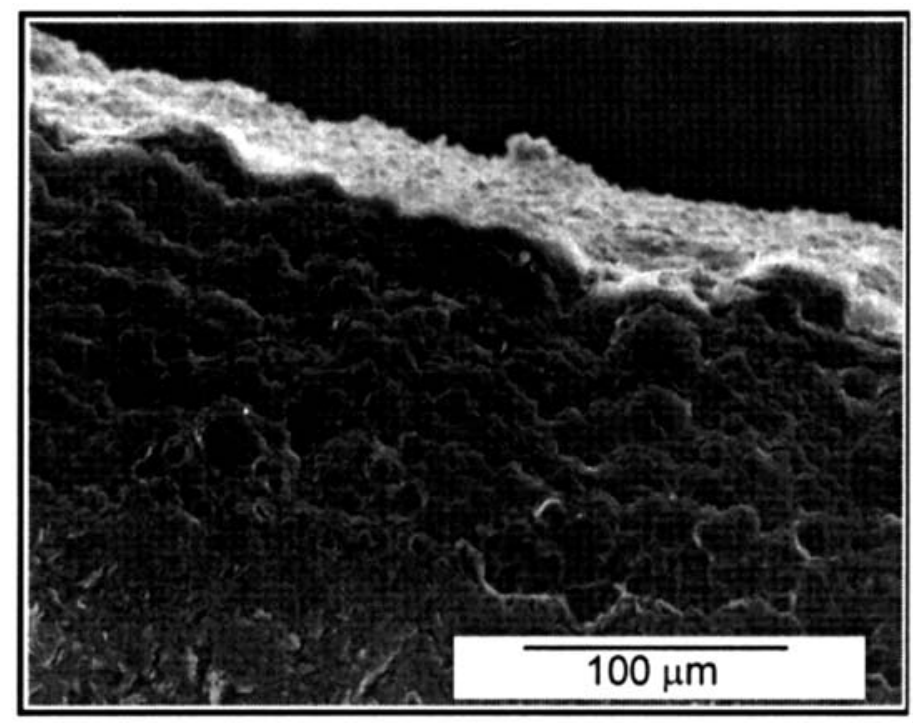

Figura 4: Micrografia obtida por MEV da seção transversal de um revestimento de carbeto de tântalo sobre grafite, obtido por eletrólise em meio de fluoretos fundidos, seguida de tratamento térmico à $2100^{\circ} \mathrm{C}$.

[Figure 4: SEM micrograph of the cross-section of a tantalum carbide coating on graphite, obtained from molten fluoride electrolysis followed by termal treatment at $2100^{\circ} \mathrm{C}$.]

As condições de operação: densidade de corrente de $20 \mathrm{~mA} \cdot \mathrm{cm}^{-2}$, temperatura de $750{ }^{\circ} \mathrm{C}$ e tempo de duração da eletrólise de 120 minutos, podem ser consideradas adequadas para o eletrorrevestimento de tubos de grafite com tântalo.

A Fig. 2 apresenta o difratograma de raios X, através do qual pôdese confirmar a formação de carbeto de tântalo, após tratamento térmico.

A Fig. 3 apresenta o tubo cortado longitudinalmente, onde observa-se uma morfologia de grão nodular. O exame da seção transversal do tubo de grafite eletrorrevestido (Fig. 4), revelou uma interface (carbeto de tântalo/grafite) bem definida, com boa aderência entre o depósito e o substrato, e ausência de porosidades e incrustações. A espessura do revestimento de carbeto de tântalo foi de aproximadamente $26 \mu \mathrm{m}$; a espessura da camada depositada é 
uma medida importante na técnica de eletrólise: o revestimento deve ser espesso o suficiente para conferir inércia química ao tubo de grafite, e ao mesmo tempo, não interferir em suas propriedades elétricas. A grande vantagem desta metodologia é a possibilidade de controlar a espessura da camada depositada de tântalo, e portanto da camada de carbeto de tântalo (após tratamento térmico), em função dos parâmetros eletroquímicos densidade de corrente e tempo de eletrólise.

A dificuldade observada nesta técnica foi a remoção do tubo de grafite do suporte do cátodo, após a eletrólise.

\section{CONCLUSÕES}

A técnica da eletrólise em meio de fluoretos fundidos à temperatura de $750{ }^{\circ} \mathrm{C}$, sob atmosfera de argônio, em densidade de corrente de $20 \mathrm{~mA} \cdot \mathrm{cm}^{-2}$ e tempo de 120 minutos, foi efetiva para a formação do revestimento de tântalo. $\mathrm{O}$ depósito obtido pode ser considerado adequado analiticamente, por ser liso, aderente, homogêneo, sem porosidades, incrustações ou microtrincas.

O tratamento térmico realizado em atmosfera de argônio com
$3 \times 10^{-8} \mathrm{MPa}$ e temperatura de aproximadamente $2100^{\circ} \mathrm{C}$ possibilitou a formação de uma perfeita camada de carbeto de tântalo.

\section{REFERÊNCIAS}

[1] A. B. Volsky, Spectrochim. Acta 8 (1995) 1417.

[2] G. W. Mellors; S. Senderoff, Plating 51 (1964) 972.

[3] G. W. Mellors; S. Senderoff; W. J. Reinhart, J. Electrochem. Soc. 112, 8 (1965) 840.

[4] P. Los, J. Josiak, A. Bogacz, W. Szklarski, Archiwum Hutnictwa 29, 4 (1984) 515.

[5] P. Taxil, J. Mahenc, J. Appl. Electrochem. 17 (1987) 261.

[6] D. V. B. S. Pinto, "Eletrorrevestimento de substratos metálicos com tântalo em meio de fluoretos fundidos; caracterização física e eletroquímica dos revestimentos". Instituto de Química - USP, São Paulo, Tese de Doutorado (1998).

[7] A. F. Sartori, "Eletrodeposição de nióbio em meio de fluoretos fundidos", Instituto de Química - USP, Tese de Doutorado (1987).

(Rec. 26/10/1999, Rev. 03/04/2001, Ac. 20/04/2001) 